\title{
Association of Comorbidity with Depression Treatment Adequacy among Privately Insured Patients Initiating Depression Treatment
}

\author{
Yong Joo Rhee1,2, Mara Gustafson², Michael Ziffra2 ${ }^{2}$, David C. Mohr2,3,4, Neil Jordan',3,5,6 \\ ${ }^{1}$ Department of Health Sciences, Dongduk Women's University, Seoul, Korea \\ ${ }^{2}$ Department of Psychiatry and Behavioral Sciences, Feinberg School of Medicine, Northwestern University, \\ Chicago, IL, USA \\ ${ }^{3}$ Department of Preventive Medicine, Feinberg School of Medicine, Northwestern University, Chicago, IL, USA \\ ${ }^{4}$ Center for Behavioral Intervention Technologies (CBITs), Northwestern University, Chicago, IL, USA \\ ${ }^{5}$ Center for Healthcare Studies, Institute for Public Health and Medicine, Feinberg School of Medicine, \\ Northwestern University, Chicago, IL, USA \\ ${ }^{6}$ Center for Innovation in Complex Chronic Healthcare, Hines VA Hospital, Hines, IL, USA \\ Email:yrh759@dongduk.ac.kr, yongjoo.rhee@gmail.com
}

Received 19 March 2015; accepted 28 April 2015; published 4 May 2015

Copyright (C) 2015 by authors and Scientific Research Publishing Inc.

This work is licensed under the Creative Commons Attribution International License (CC BY).

http://creativecommons.org/licenses/by/4.0/

(c) (i) Open Access

\section{Abstract}

This study examined the association among comorbidity, type of depression treatment, and depression treatment adequacy among privately insured depression patients using claims data from 165,569 employees. Individuals newly diagnosed with depression $(n=2364)$ were identified using ICD-9 diagnosis codes. Logistic regression models were used to determine if certain medical and psychiatric comorbidities were associated with depression treatment type (medication only, psychotherapy only, or combined treatment) and treatment adequacy. Approximately half of the sample $(56.7 \%)$ received medication only, $26.8 \%$ received psychotherapy and medication, and $16.5 \%$ received psychotherapy only. The medication only group had the highest rate $(50.2 \%)$ of receiving minimally adequate treatment, while those who received the combined treatment had the lowest rate $(21.0 \%)$. Patients with comorbid anxiety disorders were significantly more likely to receive combined treatment or psychotherapy alone. Those who had comorbid musculoskeletal pain were significantly more likely to receive combined treatment. After controlling for treatment type, patients with comorbid diabetes and asthma had higher rates of receiving adequate treatment than patients with other comorbid conditions. There is a continous need for practice-system level in- 
terventions to improve the proportion of privately insured patients with new depressive episodes who receive adequate depression treatment.

\author{
Keywords
}

Depression, Comorbidity, Treatment Adequacy

\title{
1. Introduction
}

Depression is a common and costly problem in American workplace (Kessler, Merikangas, \& Wang, 2008). Beyond the employer health care costs associated with depression, several reviews of the literature suggest a close association between depression and decreased occupational functioning (Lagerveld et al., 2010; Simon, 2003). Depression is significantly associated with increased absenteeism and lost productivity while at work (Kessler, Greenberg, Mickelson, Meneades, \& Wang, 2001; Kessler et al., 2008; Stewart, Ricci, Chee, Hahn, \& Morganstein, 2003), which together result in an estimated annual loss of 225 million workdays, and \$36.6 billion in salary-equivalent lost productivity (Kessler et al., 2008).

While effective treatment exists in the form of medication and psychotherapy (American Psychiatric Association, 2000; Hepner et al., 2007), most working individuals diagnosed with major depression do not receive sufficient treatment (Kessler et al., 2008). In fact, when examined against national guidelines for the treatment of major depression, the studies of large-scale community indicate that only $22 \%$ - $26 \%$ of adults with major depression receive minimally adequate treatment (Kessler et al., 2003; Young, Klap, Sherbourne, \& Wells, 2001), and many adults delay treatment (Ki et al., 2014).

Various patient-level factors have been associated with receiving insufficient depression treatment, including race, age, and insurance status. African Americans and older adults have been shown to be significantly less likely to receive guideline concordant depression care, and uninsured individuals less likely to initiate any type of depression treatment (Alegria et al., 2008; Harman, Edlund, \& Fortney, 2004). Patient adherence behaviors also interfere with the delivery of adequate depression treatment. Patient-level predictors associated with lower adherence to antidepressant medication include younger age (Edlund et al., 2002), fewer years of education (Olfson, Marcus, Tedeschi, \& Wan, 2006), minority status (Arnow et al., 2007; Olfson et al., 2006; Warden et al., 2007), better perceived physical functioning (Warden et al., 2009), and type of medication (Machado, Iskedjian, Ruiz, \& Einarson, 2006; Tai-Seale, Croghan, \& Obenchain, 2000). Lower adherence to psychotherapy is associated with all but the final two of the above patient-level factors (Arnow et al., 2007; Edlund et al., 2002), and is further affected by referral source (Hampton-Robb, Qualls, \& Compton, 2003), poorer therapeutic alliance (Arnow et al., 2007), and perceived practical barriers to treatment (e.g. cost, transportation) (Mohr et al., 2006).

In depression treatment lasting longer than 12 weeks, adherence appears to increase when the intervention is a combined medication-psychotherapy approach as opposed to medication alone (Pampallona, Bollini, Tibaldi, Kupelnick, \& Munizza, 2004). Where individuals receive care is another characteristic associated with depression treatment adherence. Multiple studies suggest that patients receive adequate levels of treatment significantly more often when seeing mental health specialists (psychiatrists, psychologists, or mental health practitioners) either alone or in conjunction with primary care physicians as compared to those receiving treatment solely from the general medical sector (Jordan, Lee, Valenstein, \& Weiss, 2007; Wang et al., 2005; Weilburg et al., 2003).

One important patient-level factor that can impact provider and intervention-level variables is the presence of psychiatric or physical health comorbid conditions. Depression has been shown to be significantly associated with physical comorbidities across all general diagnostic categories (Stranges et al., 2009), as well as multiple psychiatric comorbidities (Hasin, Goodwin, Stinson, \& Grant, 2005; Kessler et al., 2003). Depression can worsen the prognosis of physical comorbidities (Evans \& Charney, 2003; Simon, 2003), substantially increase medical costs (Katon, 2003), and decrease adherence to medical treatment regimens (Ciechanowski, Katon, \& Russo, 2000; DiMatteo, Lepper, \& Croghan, 2000). Some evidence suggests that patients with physical comorbidities are less likely to receive adequate depression treatment (Ettner et al., 2010; Rost et al., 2000), perhaps as a result of the presence of competing demands in a primary care setting (Klinkman, 1997). Other studies report the opposite. One Canadian study found that adults diagnosed with depression and a comorbid chronic medical dis- 
order where more likely to receive guideline-concordant care than those with no medical comorbidity (Kurdyak \& Gnam, 2004), and those with comorbid stroke or diabetes were more likely to receive psychopharmacological depression care in an American sample (Gill, Chen, \& Lieberman, 2008).

Existing data on the relationship between psychiatric comorbidity and the receipt of adequate depression treatment also suggest the need for further investigation. One complicating factor in assessing this relationship is that an examination of adherence to treatment standards incorporates information about treatment initiation and treatment completion. Psychiatric comorbidities have been shown to both increase treatment seeking behavior (du Fort et al., 1999), and increase risk for attrition (Arnow et al., 2007; Howland et al., 2009; Olfson et al., 2009; Warden et al., 2007). Furthermore, the relationship between psychiatric comorbidity and attrition is complex. The latter study only found this association when mental health treatment was received in the general medical sector, and only as a predictor of attrition before the third visit (Warden et al., 2007). When treatment was provided by a psychiatrist after three visits, psychiatric comorbidities actually reduced patient dropout from treatment. Others have found that having a psychiatric comorbidity (without an additional physical comorbidity) increased the likelihood of receiving guideline-concordant depression treatment (Ettner et al., 2010). These mixed results may be related to the finding that the effect of psychiatric comorbidity on depression treatment appears specific to the type of comorbid disorder. Whereas anxiety disorders have been shown to increase the likelihood of receiving adequate depression treatment (Young et al., 2001), comorbid personality disorders have been shown to decrease this likelihood (Mulder, 2002).

Given the worsened patient prognosis associated with physical and psychiatric comorbidities (Evans \& Charney, 2003; Howland et al., 2009), further research is needed to understand how to best deliver guideline-concordant depression treatment to an employed, privately insured population with comorbid disorders. While some progress has been made in understanding the impact of psychiatric and physical comorbid diagnoses on receiving guideline-concordant care (Ettner et al., 2010; Kurdyak \& Gnam, 2004), less is known about how specific comorbidities impact the type of treatment recommended and treatment adequacy once treatment has begun. Greater understanding of the relationship among comorbidity, treatment type, and treatment adequacy would advance health care providers' ability to make individualized, evidence-based treatment recommendations. The aim of this study is, therefore, to determine the extent to which comorbidity impacts the receipt of adequate depression care. In the population of working adults with private health insurance, the study seeks to determine how comorbidity relates to the kind of treatment received and the level of treatment adequacy.

\section{Method}

\subsection{Data and Study Cohort}

This study used medical and pharmacy claims data from the health insurance plans of a Fortune 50 company (Company A) and a large, national non-profit organization (Company B). The dataset included all claims from Company A between April 1, 2003 and March 31, 2004 and from Company B between January 1, 2003 and December 31, 2003.

The database initially contained records for 165,569 employees and their dependents. The analytic dataset for this study was limited to adults' ages of 18-64. Claims data were then used to identify patients with new depressive episodes and attendant treatment during the study period, with new episodes signified by a depressive disorder diagnosis at least three months after the initial dates in the claims data. A validated strategy involving ICD-9 codes was used to identify persons with a new depressive disorder diagnosis (Jordan et al., 2007). The diagnosis of a new depressive disorder was based on the following criteria: a) primary diagnosis of a depressive disorder (296.2x, 296.3x, 300.4x, 309, 311.xx) in any inpatient or outpatient setting; (b) a secondary diagnosis of major depression during an inpatient stay; or (c) at least two secondary diagnoses of major depression on different days within a nine-month period in any outpatient setting. Because it was not possible to identify depressive episodes that occurred prior to the time for which we have claims data, patients with a depressive disorder diagnosis during the first three months of the claims data were excluded to ensure that the analytic sample was limited to new depressive episodes. Also excluded were patients with a bipolar disorder diagnosis, due to possible misclassification with major depression, as well as patients that did not initiate any treatment for their depressive disorder within 90 days of the index date. In total, 2,364 patients met these diagnostic criteria so depressive disorder morbidity was $1.43 \%$ in this population.

Matria Health Care provided blinded medical and pharmacy claims data for this project via a contract with 
Northwestern University's Mental Health Services and Policy Program (MHSPP) for research collaboration activities. The Institutional Review Board of Northwestern University approved secondary analysis of blinded medical and pharmacy data for research purposes. Informed consent was unnecessary because the data used in the analyses were de-identified.

\subsection{Identifying Physical and Mental Comorbid Conditions}

After identifying patients diagnosed with a depressive disorder, physical and psychiatric comorbid conditions were identified from inpatient, emergency room, and outpatient medical claims using ICD-9 codes. Consistent with a previous analysis using these data (Rhee, Taitel, Walker, \& Lau, 2007), we identified the following physical health comorbid conditions: musculoskeletal pain (MSCP), injuries, hypertension, asthma, diabetes, arthritis, urinary tract infection (UTI), ischemic heart disease (IHD), coronary artery disease (CAD), arrhythmia, chronic obstructive pulmonary disease (COPD), otitis, seizure, irritable bowel syndrome, pregnancy, congestive heart failure (CHF), cancer, hepatitis C, stroke, peptic ulcer, osteoporosis, pressure ulcer, dementia, HIV, and sickle cell anemia. In addition, the following comorbid psychiatric disorders were identified: anxiety disorders, adjustment disorder, alcohol use, substance abuse, and personality disorders (Rhee et al., 2007).

\subsection{Adequacy of Depression Treatment}

The use of medication and psychotherapy treatments following the diagnosis of a depressive disorder in the study sample was then examined. Using a list of National Drug Codes (NDC) developed in a previous study (Jordan et al., 2007), antidepressant prescriptions filled during the study period were identified within the pharmacy claims data. Current Procedure Terminology codes (CPT) were used to identify psychotherapy treatment (individual, family, and group) billed for patients diagnosed with a depressive disorder in the medical claims data (Table 1).

Treatment adequacy, the key outcome of interest in this study, was defined as a binary variable within each treatment category: medication only, psychotherapy only, or combined medication and psychotherapy receipt of adequate medication treatment was defined as having at least 84 days of an antidepressant supply during the first 114 of a treatment period, which was consistent with the HEDIS 2008 guidelines for antidepressant medication management (National Committee for Quality Assurance, 2007). Because existing guidelines from the American Psychiatric Association (American Psychiatric Association, 2010) and HEDIS do not specify the most appropriate dose of psychotherapy for the initial treatment of depression, we used several meetings of the co-authors to achieve a consensus to define adequate psychotherapy treatment as having at least eight psychotherapy session claims within three months of the initial depression diagnosis (Wang et al., 2005). APA guidelines (2010) suggest that the combined use of antidepressant medication with psychotherapy may be the appropriate treatment for moderate to severe major depression, but do not specify the optimal dose of either treatment type. For this study, we defined adequate combined treatment as having received at least 84 total days of antidepressant medication supply during the first 114 days after depression diagnosis and at least eight psychotherapy sessions during the first 3 months after the initial depression diagnosis.

\subsection{Statistical Analysis}

Univariate analyses were conducted to examine the distribution of all variables. For bivariate analyses, 2-sided

Table 1. Current procedure terminology codes (CPT) for psychotherapy.

\begin{tabular}{|c|c|}
\hline CPT codes & Labels \\
\hline 90846,90847, 90849 & $\begin{array}{l}\text { family medical psychotherapy (conjoint psychotherapy) by a physician, with continuing medical diagnostic } \\
\text { evaluation, and drug management when indicated. }\end{array}$ \\
\hline 90853, 90857 & $\begin{array}{l}\text { group medical psychotherapy by a physician, with continuing medical diagnostic evaluation, and drug man- } \\
\text { agement when indicated. }\end{array}$ \\
\hline $90810,90812,90814$ & $\begin{array}{l}\text { Individual psychotherapy insight-oriented, behavior modifying and/or supportive, in an office or outpatient } \\
\text { facility, face-to-face with the patient. }\end{array}$ \\
\hline 90804, 90806 & Individual psychotherapy, insight oriented, behavior modifying and/or supportive, in an office or outpatient facility. \\
\hline
\end{tabular}


t-tests were performed on continuous variables and $\chi^{2}$ tests on categorical variables. Multinominal logistic regression was used to examine which factors were associated with having received each of the three treatment types. Logistic regression was used to identify the risk factors associated with treatment adequacy. Multicollinearity among independent variables was examined and was not problematic. All data analyses were conducted at the patient level using SAS version 9.2 (SAS, 2009). Age, gender, and patient's employer were controlled in all analyses.

\section{Results}

\subsection{Descriptive Characteristics}

Among the 2,364 patients diagnosed with a depressive disorder, 73\% were female with an average age of 42.8 years $(\mathrm{SD}=12.6$, a range from 18 to 64 years old). The average age of females and males in the study sample was $42.8(\mathrm{SD}=12.6)$ and $42.4(\mathrm{SD}=13.6)$ years old, respectively (Table 2). Approximately half of the patients (56.7\%) were treated solely with medication, while $26.8 \%$ of patients received combined treatment of psychotherapy and medication. Only $16.5 \%$ of patients received psychotherapy without medication.

Table 2. Descriptive characteristics (\% unless otherwise specified) $(n=2364)$.

\begin{tabular}{|c|c|c|c|c|}
\hline & $\begin{array}{l}\text { Medication Only } \\
\quad(\mathrm{n}=1341)\end{array}$ & $\begin{array}{l}\text { Psychotherapy Only } \\
\qquad(\mathrm{n}=390)\end{array}$ & $\begin{array}{c}\text { Medication and } \\
\text { Psychotherapy }(n=633)\end{array}$ & $\begin{array}{c}\text { Total } \\
(\mathrm{n}=2,364)\end{array}$ \\
\hline Mean Age (SD)* & $42.7(12.6)$ & $41.7(13.4)$ & $43.7(12.0)$ & $42.8(12.6)$ \\
\hline Female & 73.5 & 68.7 & 73.6 & 73 \\
\hline \multicolumn{5}{|l|}{ Company^ } \\
\hline A & 52.7 & 51.7 & 62.1 & 55.1 \\
\hline B & 47.3 & 48.2 & 37.9 & 44.9 \\
\hline \multicolumn{5}{|l|}{ Psychiatric Comorbidity } \\
\hline Anxiety disorder & 19.5 & 35.1 & 33.0 & 25.7 \\
\hline Adjustment disorder & 8.1 & 10.3 & 10.0 & 9.0 \\
\hline Alcohol use disorder & 3.4 & 1.5 & 4.7 & 3.5 \\
\hline Other mental health conditions & 2.0 & 2.1 & 2.5 & 2.1 \\
\hline \multicolumn{5}{|l|}{ Physical Comorbidity } \\
\hline Musculoskeletal conditions & 29.9 & 27.4 & 37.6 & 31.5 \\
\hline Injuries & 17.5 & 18.2 & 18.3 & 17.8 \\
\hline Hypertension & 13.6 & 10.0 & 15.6 & 13.5 \\
\hline Asthma & 6.9 & 5.9 & 7.7 & 6.9 \\
\hline Diabetes & 6.5 & 4.6 & 7.6 & 6.5 \\
\hline Arthritis & 4.8 & 4.6 & 7.3 & 5.5 \\
\hline Ischemic heart disease & 3.6 & 1.8 & 4.3 & 3.5 \\
\hline Coronary artery disease & 2.6 & 0.8 & 4.1 & 2.7 \\
\hline Other physical health problems & 14.5 & 14.9 & 16.9 & 15.4 \\
\hline \multicolumn{5}{|l|}{ Source of Depression Diagnosis } \\
\hline Outpatient & 95.9 & 98.5 & 96.8 & 97.2 \\
\hline Inpatient & 4.1 & 1.5 & 3.2 & 2.9 \\
\hline Treatment Adequacy & 50.2 & 34.4 & 21.0 & 35.2 \\
\hline
\end{tabular}

*Age range was from 18 to 64 years old; average age among females was $42.9(\mathrm{SD}=12.1)$, and average age among males was $42.4(\mathrm{SD}=13.1) . \wedge$ Company A was a Fortune 50 company, and Company B was a large, national non-profit organization. 
The most frequent comorbid conditions among the study cohort were musculoskeletal pain (31.5\%), anxiety disorders (25.7\%), injuries (17.8\%), hypertension (13.5\%), asthma (6.9\%), diabetes (6.5\%), arthritis (5.5\%), and alcohol use disorder (3.5\%).

The medication only group had the highest treatment adequacy rate (50.2\%). Approximately one-third (34.4\%) of patients in the psychotherapy only group received adequate treatment, and patients who received both antidepressants and psychotherapy had the lowest treatment adequacy rate (21.0\%).

\subsection{Predictors of Depression Treatment Group}

There were several significant characteristics associated with depression treatment group (Table 3). Patients with a comorbid anxiety disorder were significantly more likely to receive psychotherapy only (RRR $=2.35,95 \%$ CI $[1.83,3.03])$ or a combined treatment of medication and psychotherapy (RRR $=1.94,95 \%$ CI $[1.56,2.41])$ rather than medication alone. Patients who had comorbid musculoskeletal pain were significantly more likely to receive medication and psychotherapy for their depressive disorder instead of medication alone (RRR $=1.35,95 \%$ CI $[1.08,1.69])$ or psychotherapy alone (RRR $=1.41,95 \%$ CI $[1.04,1.91])$. Patients with comorbid alcohol use disorder were significantly more likely to receive a combined treatment of medication and psychotherapy for their depressive disorder rather than psychotherapy alone (RRR $=3.51,95 \%$ CI $[1.22,10.06])$. Patients with comorbid coronary artery disease were also significantly more likely to receive medication and psychotherapy rather than psychotherapy alone $(\mathrm{RRR}=4.81,95 \% \mathrm{CI}[1.01-23.03])$.

\subsection{Predictors of Depression Treatment Adequacy}

Of the comorbid conditions identified, two were significantly associated with depression treatment adequacy after controlling for treatment group (Table 4). Patients with comorbid diabetes had significantly higher odds of receiving adequatedepression treatment $(\mathrm{OR}=1.77,95 \% \mathrm{CI}[1.21,2.57])$, as did patients with comorbid asthma $(\mathrm{OR}=1.53,95 \% \mathrm{CI}[1.08,2.17])$.

\section{Table 3. Predictors of depression treatment group^.}

\begin{tabular}{|c|c|c|c|c|c|c|c|c|c|}
\hline \multirow[t]{2}{*}{ Condition } & \multicolumn{3}{|c|}{$\begin{array}{l}\text { Medication and Psychotherapy } \\
\text { vs. Medication Only }\end{array}$} & \multicolumn{3}{|c|}{$\begin{array}{l}\text { Psychotherapy Only vs. } \\
\text { Medication Only }\end{array}$} & \multicolumn{3}{|c|}{$\begin{array}{l}\text { Medication and Psychotherapy } \\
\text { vs. Psychotherapy Only }\end{array}$} \\
\hline & $\mathrm{RRR}^{1}$ & $95^{\circ}$ & $6 \mathrm{CI}$ & RRR & $95 \%$ & $6 \mathrm{CI}$ & RRR & $95 \%$ & $\% \mathrm{CI}$ \\
\hline Anxiety disorder & $1.937 * * *$ & 1.557 & 2.410 & $2.352^{* * *}$ & 1.825 & 3.031 & 0.824 & 0.626 & 1.083 \\
\hline Adjustment disorder & 1.246 & 0.893 & 1.739 & 1.298 & 0.141 & 1.069 & 0.960 & 0.626 & 1.471 \\
\hline Alcohol use disorder & 1.359 & 0.746 & 2.477 & 0.388 & 0.141 & 1.069 & $3.505^{*}$ & 1.221 & 10.060 \\
\hline $\begin{array}{l}\text { Other mental health } \\
\text { conditions }\end{array}$ & 0.939 & 0.444 & 1.987 & 1.521 & 0.600 & 3.856 & 0.618 & 0.222 & 1.717 \\
\hline $\begin{array}{l}\text { Musculoskeletal } \\
\text { conditions }\end{array}$ & $1.352^{* *}$ & 1.082 & 1.688 & 0.958 & 0.726 & 1.264 & $1.412 *$ & 1.042 & 1.912 \\
\hline Injuries & 0.952 & 0.733 & 1.240 & 1.153 & 0.843 & 1.576 & 0.828 & 0.583 & 1.172 \\
\hline Hypertension & 0.994 & 0.736 & 1.342 & 0.767 & 0.514 & 1.145 & 1.296 & 0.840 & 1.997 \\
\hline Asthma & 1.029 & 0.709 & 1.496 & 0.845 & 0.520 & 1.374 & 1.218 & 0.718 & 2.065 \\
\hline Diabetes & 1.138 & 0.762 & 1.689 & 0.845 & 0.489 & 1.461 & 1.347 & 0.747 & 2.428 \\
\hline Arthritis & 1.305 & 0.858 & 1.985 & 1.080 & 0.610 & 1.910 & 1.208 & 0.664 & 2.199 \\
\hline Ischemic heart disease & 0.697 & 0.312 & 1.560 & 0.860 & 0.310 & 2.387 & 0.811 & 0.255 & 2.574 \\
\hline $\begin{array}{l}\text { Coronary artery } \\
\text { disease }\end{array}$ & 1.873 & 0.780 & 4.497 & 0.389 & 0.088 & 1.718 & $4.812^{*}$ & 1.007 & 23.027 \\
\hline $\begin{array}{l}\text { Other physical health } \\
\text { problems }\end{array}$ & 1.040 & 0.788 & 1.372 & 1.185 & 0.848 & 1.659 & 0.877 & 0.606 & 1.269 \\
\hline $\begin{array}{l}\text { Depression } \mathrm{dx} \text { in } \\
\text { inpatient setting }\end{array}$ & 0.578 & 0.323 & 1.036 & 0.425 & 0.173 & 1.041 & 1.361 & 0.509 & 0.636 \\
\hline
\end{tabular}

${ }^{*} p<0.05,{ }^{* *} p<0.01,{ }^{* * *} p<0.001 ; \wedge$ Results are adjusted for age, gender, and employer.

${ }^{1}$ Relative risk ratio, which is interpreted similar to an odds ratio. 
Table 4. Predictors of depression treatment adequacy.

\begin{tabular}{|c|c|c|c|}
\hline & $\mathrm{OR}^{\star}$ & $95 \%$ & $6 \mathrm{CI}$ \\
\hline Anxiety & 1.168 & 0.948 & 1.439 \\
\hline Adjustment disorder & 0.992 & 0.725 & 1.358 \\
\hline Alcohol use disorder & 1.120 & 0.612 & 2.049 \\
\hline Other mental health conditions & 1.029 & 0.507 & 2.087 \\
\hline Musculoskeletal conditions & 1.156 & 0.938 & 1.425 \\
\hline Injuries & 0.911 & 0.714 & 1.162 \\
\hline Hypertension & 0.821 & 0.617 & 1.089 \\
\hline Asthma & $1.528^{*}$ & 1.075 & 2.171 \\
\hline Diabetes & $1.767 * *$ & 1.213 & 2.573 \\
\hline Arthritis & 1.081 & 0.720 & 1.625 \\
\hline Ischemic heart disease & 0.959 & 0.468 & 1.962 \\
\hline Coronary artery disease & 0.723 & 0.313 & 1.670 \\
\hline Other physical health problems & 1.075 & 0.831 & 1.392 \\
\hline Both vs. RX Only & $0.209 * * *$ & 0.165 & 0.264 \\
\hline Psychotherapy Only vs. RX Only & $0.504 * * *$ & 0.394 & 0.646 \\
\hline
\end{tabular}

${ }^{\star}$ Odds Ratio ${ }^{*} p<0.05,{ }^{* *} p<0.01,{ }^{* * *} p<0.001 ; \wedge$ Results are adjusted for age, gender, employer, and depression treatment group.

\section{Discussion}

Consistent with findings in recent large-scale epidemiological studies (Kessler et al., 2003; Young et al., 2001), the majority of the patients in this study did not receive treatment consistent with national guidelines. Among the 2364 patients diagnosed with a depressive disorder in this study's sample, only half of the patients in the medication only group received adequate treatment. This finding is consistent with other studies of antidepressant medication adequacy in privately insured populations (Akincigil et al., 2007; Busch, Leslie, \& Rosenheck, 2004). Only about one-third of patients who received psychotherapy alone received an adequate treatment. Those receiving a combined form of treatment had the lowest treatment adequacy rate (21\%). A meta-analysis of treatment adherence in studies of patients receiving pharmacotherapy or combined treatment for depression found no difference in adherence rates for interventions lasting less than 12 weeks, but higher adherence for combined treatments in those last longer than this period (Pampallona et al., 2004). The differing findings in this study may be accounted for by varying definitions of adherence and adequacy across studies. In our analysis, medication treatment was considered adequate if prescriptions were filled, and not if medication was actually taken, whereas adequate psychotherapy required actual participation in eight therapy sessions. Therefore, the higher adequacy rates for the medication only group may reflect the significantly lower barriers associated with filling three prescriptions as compared to attending eight psychotherapy appointments.

Several physical and psychiatric comorbidities were significantly associated with the type of treatment that participants received. Comorbid musculoskeletal pain was more strongly associated with the receipt of combined treatment compared to the receipt of medication alone. This finding is consistent with literature that has demonstrated the efficacy of certain forms of psychotherapy in reducing the experience of pain among chronic pain patients (Vowles \& McCracken, 2008). Alternatively, a combined approach to treatment may have been recommended for this patient population given the higher risk of substance abuse among individuals with comorbid chronic pain and depression (Manchikanti et al., 2007).

Individuals diagnosed with comorbid alcohol use disorder were more likely to receive combined treatment than psychotherapy alone. The increased risk of suicidality, more frequent depressive episodes, and more severe depressive symptoms associated with a comorbid substance use disorder (Davis, Uezato, Newell, \& Frazier, 2008) may increase the likelihood of practitioners recommending combined treatment. Comorbid anxiety carries similar risk of greater symptom severity and increased incidence of suicidality, and has also been associated 
with decreased efficacy of antidepressant treatment and increased negative side effects of antidepressant medication (Fava et al., 2008). The greater risks and symptom severity of this comorbidity may account for the creased likelihood of combined treatment in our study sample, whereas the negative effect on antidepressant treatment may account for the increased likelihood of psychotherapy only treatment.

Patients with comorbid diabetes or asthma had significantly higher odds of receiving adequate depression treatment. While studies have indicated that comorbid depression is associated with lower adherence to diabetes care (Gonzalez et al., 2008; Sung et al., 2014), much less is known about the relationship between these two medical diagnoses and adequacy of depression treatment. It is possible that individuals with chronic medical comorbidities have more opportunities to receive depression treatment or referrals from their physicians, though it is noteworthy that depression treatment adequacy varied across the chronic medical conditions considered in this study. It is also possible that chronic conditions requiring significant self-care, such as asthma and diabetes, might also lead to a higher likelihood of depression treatment adequacy among patients more adherent to their self-care.

\section{Limitations}

There are several limitations associated with this study. The health insurance datasets employed in this study were limited to one year of medical and pharmacy claims data. It was therefore not possible to precisely distinguish those individuals receiving their first ever diagnosis of a depressive disorder from those who experienced recurrent depressive episodes. For this reason, we limited the sample to individuals who received a new diagnosis of depression at least three months after the beginning of the study period to increase the likelihood that subjects' diagnoses reflected a discrete depressive episode rather than a historic diagnosis. Also due to the nature of the administrative claims data used in this study, incomplete treatment information was available. It was not possible to determine if subjects were employing other types of treatments for their depression beyond medication and insurance-billed psychotherapy.

It was also not possible to determine if those individuals filling prescriptions were in fact taking their medications. This limitation may have led to a bias in the findings, with an overestimate of the adequacy of antidepressant treatment received. While prescription fills are an imperfect measure of medication treatment adequacy, the use of large claims datasets necessitates this type of operationalization, and it has been used in previous similar studies in the past (Ettner et al., 2010). The type of depression treatment should ideally align with the severity of depression symptoms. Because claims data do not allow us to accurately assess depression severity, the focus of this study is the treatment adequacy for each of the three most common depression treatment approaches. Additionally, although lower medication and psychotherapy adherence are associated with fewer years of education and minority status (Warden et al., 2009), we are not able to examine these factors because our dataset lacks data on education level and race/ethnicity. Although the data used in this study are 10 years old and there have been changes in diagnostic strategies for several common comorbid conditions, depression treatment has not substantially changed during this time (American Psychiatric Association, 2000, 2010). Finally, because our study sample included employees from two private insurance health plans, our findings may not generalize beyond this population.

\section{Conclusions}

The findings of this study suggest several important implications for behavioral health services. First, the majority of individuals in this study who were diagnosed with a depressive disorder did not receive an adequate dose of pharmacological and/or psychotherapeutic treatment for their depression. Given this finding, there is a continous need for practice-system level interventions to improve the proportion of privately insured patients with new depressive episodes and other comorbid conditions that receive adequate depression treatment. In particular, given that individuals receiving psychotherapy alone or in combination with medication were less likely to receive adequate treatment than those receiving only medication, there should be special emphasis on improving the receipt of psychotherapy among privately insured patients with depression and other comorbid conditions. If combined psychotherapy and medication appears to be the optimal treatment for certain types of depression (Pampallona et al., 2004), it is possible that addressing the barriers to psychotherapy in particular would help advance the delivery of best-practice treatment for depression. Innovative means of delivering psychotherapy, including via telephone rather than face-to-face, have demonstrated improved adherence rates, and may be a 
possible solution to reduce barriers to psychotherapeutic treatment such as time, travel, and financial cost (Mohr et al., 2006). Further research is also needed to understand the provider-level factors that are associated with low usage of combined treatment for depression among these privately insured patients. While some research focus has been devoted to patient-level factors that impact treatment adequacy, far fewer studies have been devoted to understanding what barriers prevent practitioners from facilitating this optimal intervention for depression treatment.

This study also suggests the possible adaptive strength that could be found in being diagnosed with certain comorbid physical conditions along with a depressive disorder, chiefly asthma and diabetes. While depression's deleterious effects on various physical conditions has been well documented, this study suggests that patients who are more engaged in care for their comorbid conditions may be more likely to receive adequate depression treatment.

\section{Acknowledgements}

Matria Health Care provided blinded medical and pharmacy claims data for this project.

\section{References}

Akincigil, A., Bowblis, J. R., Levin, C., Walkup, J. T., Jan, S., \& Crystal, S. (2007). Adherence to Antidepressant Treatment among Privately Insured Patients Diagnosed With Depression. Medical Care, 45, 363-369. http://dx.doi.org/10.1097/01.mlr.0000254574.23418.f6

Alegria, M., Chatterji, P., Wells, K., Cao, Z., Chen, C. N., Takeuchi, D., \& Meng, X. L. (2008). Disparity in Depression Treatment among Racial and Ethnic Minority Populations in the United States. Psychiatric Services, 59, 1264-1272. http://dx.doi.org/10.1176/ps.2008.59.11.1264

American Psychiatric Association (2000). American Psychiatric Association Practice Guideline for the Treatment of Patients with Major Depressive Disorder. American Journal of Psychiatry, 157, 1-45.

American Psychiatric Association (2010). Practice Guideline for the Treatment of Patients with Major Depressive Disorder (3rd ed.). Arlington,VA: American Psychiatric Association.

Arnow, B. A., Blasey, C., Manber, R., Constantino, M. J., Markowitz, J. C., Klein, D. N., \& Rush, A. J. (2007). Dropouts versus Completers among Chronically Depressed Outpatients. Journal of Affective Disorders, 97, 197-202. http://dx.doi.org/10.1016/j.jad.2006.06.017

Busch, S. H., Leslie, D., \& Rosenheck, R. (2004). Measuring Quality of Pharmacotherapy for Depression in a National Health Care System. Medical Care, 42, 532-542. http://dx.doi.org/10.1097/01.mlr.0000128000.96869.1e

Ciechanowski, P. S., Katon, W. J., \& Russo, J. E. (2000). Depression and Diabetes: Impact of Depressive Symptoms on Adherence, Function, and Costs. Archives of Internal Medicine, 160, 3278-3285. http://dx.doi.org/10.1001/archinte.160.21.3278

Davis, L., Uezato, A., Newell, J. M., \& Frazier, E. (2008). Major Depression and Comorbid Substance Use Disorders. Current Opinion in Psychiatry, 21, 14-18. http://dx.doi.org/10.1097/YCO.0b013e3282f32408

DiMatteo, M. R., Lepper, H. S., \& Croghan, T. W. (2000). Depression Is a Risk Factor for Noncompliance with Medical Treatment: Meta-Analysis of the Effects of Anxiety and Depression on Patient Adherence. Archives of Internal Medicine, 160, 2101-2107. http://dx.doi.org/10.1001/archinte.160.14.2101

du Fort, G., Newman, S. C., Boothroyd, L. J., \& Bland, R. C. (1999). Treatment Seeking for Depression: Role of Depressive Symptoms and Comorbid Psychiatric Diagnoses. Journal of Affective Disorders, 52, 31-40. http://dx.doi.org/10.1016/S0165-0327(98)00052-4

Edlund, M. J., Wang, P. S., Berglund, P. A., Katz, S. J., Lin, E., \& Kessler, R. C. (2002). Dropping out of Mental Health Treatment: Patterns and Predictors among Epidemiological Survey Respondents in the United States and Ontario. The American Journal of Psychiatry, 159, 845-851. http://dx.doi.org/10.1176/appi.ajp.159.5.845

Ettner, S. L., Azocar, F., Branstrom, R. B., Meredith, L. S., Zhang, L., \& Ong, M. K. (2010). Association of General Medical and Psychiatric Comorbidities with Receipt of Guideline-Concordant Care for Depression. Psychiatric Services, 61, 1255-1259. http://dx.doi.org/10.1176/ps.2010.61.12.1255

Evans, D. L., \& Charney, D. S. (2003). Mood Disorders and Medical Illness: A Major Public Health Problem. Biological Psychiatry, 54, 177-180. http://dx.doi.org/10.1016/S0006-3223(03)00639-5

Fava, M., Rush, A. J., Alpert, J. E., Balasubramani, G. K., Wisniewski, S. R., Carmin, C. N., Howland, R. et al. (2008). Difference in Treatment Outcome in Outpatients with Anxious versus Nonanxious Depression: A STAR*D Report. The American Journal of Psychiatry, 165, 342-351. http://dx.doi.org/10.1176/appi.ajp.2007.06111868 
Gill, J. M., Chen, Y. X., \& Lieberman, M. I. (2008). Management of Depression in Ambulatory Care for Patients with Medical Co-Morbidities: A Study from a National Electronic Health Record (EHR) Network. International Journal of Psychiatry in Medicine, 38, 203-215. http://dx.doi.org/10.2190/PM.38.2.g

Gonzalez, S., Safren, S. A., Delahanty, L. M., Cagliero, E., Wexler, D. J., Meigs, J. B. et al. (2008). Symptoms of Depression Prospectively Predict Poorer Self-Care in Patients with Type 2 Diabetes. Diabetic Medicine, 25, 1102-1107. http://dx.doi.org/10.1111/j.1464-5491.2008.02535.x

Hampton-Robb, S., Qualls, R. C., \& Compton, W. C. (2003). Predicting First-Session Attendance: The Influence of Referral Source and Client Income. Psychotherapy Research, 13, 223-233.

Harman, J. S., Edlund, M. J., \& Fortney, J. C. (2004). Disparities in the Adequacy of Depression Treatment in the United States. Psychiatric Services, 55, 1379-1385. http://dx.doi.org/10.1176/appi.ps.55.12.1379

Hasin, D. S., Goodwin, R. D., Stinson, F. S., \& Grant, B. F. (2005). Epidemiology of Major Depressive Disorder: Results from the National Epidemiologic Survey on Alcoholism and Related Conditions. JAMA Psychiatry, 62, 1097-1106. http://dx.doi.org/10.1001/archpsyc.62.10.1097

Hepner, K. A., Rowe, M., Rost, K., Hickey, S. C., Sherbourne, C. D., Ford, D. E., Meredith, L. S., \& Rubenstein, L. V. (2007). The Effect of Adherence to Practice Guidelines on Depression Outcomes. Annals of Internal Medicine, 147, 320-329. http://dx.doi.org/10.7326/0003-4819-147-5-200709040-00007

Howland, R. H., John Rush, A., Wisniewski, S. R., Trivedi, M. H., Warden, D., Fava, M., Berman, S. R. et al. (2009). Concurrent Anxiety and Substance Use Disorders among Outpatients with Major Depression: Clinical Features and Effect on Treatment Outcome. Drug and Alcohol Dependence, 99, 248-260. http://dx.doi.org/10.1016/j.drugalcdep.2008.08.010

Jordan, N., Lee, T. A., Valenstein, M., \& Weiss, K. B. (2007). Effect of Care Setting on Evidence-Based Depression Treatment for Veterans with COPD and Comorbid Depression. Journal of General Internal Medicine, 22, 1447-1452. http://dx.doi.org/10.1007/s11606-007-0328-8

Katon, W. J. (2003). Clinical and Health Services Relationships between Major Depression, Depressive Symptoms, and General Medical Illness. Biological Psychiatry, 54, 216-226. http://dx.doi.org/10.1016/S0006-3223(03)00273-7

Kessler, R. C., Berglund, P., Demler, O., Jin, R., Koretz, D., Merikangas, K. R., Wang, P. S. et al. (2003). The Epidemiology of Major Depressive Disorder: Results from the National Comorbidity Survey Replication (NCS-R). JAMA, 289, 30953105. http://dx.doi.org/10.1001/jama.289.23.3095

Kessler, R. C., Greenberg, P. E., Mickelson, K. D., Meneades, L. M., \& Wang, P. S. (2001). The Effects of Chronic Medical Conditions on Work Loss and Work Cutback. Journal of Occupational and Environmental Medicine, 43, 218-225. http://dx.doi.org/10.1097/00043764-200103000-00009

Kessler, R. C., Merikangas, K. R., \& Wang, P. S. (2008). The Prevalence and Correlates of Workplace Depression in the National Comorbidity Survey Replication. Journal of Occupational and Environmental Medicine, 50, 381-390. http://dx.doi.org/10.1097/JOM.0b013e31816ba9b8

Ki, M., Paik, J. W., Choi, K. S., Ryu, S. H., Han, C., Lee, K., Ham, B. J., Chang, H. S., Won, E. S., Jun, T. Y., \& Lee, M. S. (2014). Delays in Depression Treatment among Korean Population. Asia-Pacific Psychiatry, 6, 414-424. http://dx.doi.org/10.1111/appy.12140

Klinkman, M. S. (1997). Competing Demands in Psychosocial Care: A Model for the Identification and Treatment of Depressive Disorders in Primary Care. General Hospital Psychiatry, 19, 98-111. http://dx.doi.org/10.1016/S0163-8343(96)00145-4

Kurdyak, P. A., \& Gnam, W. H. (2004). Medication Management of Depression: The Impact of Comorbid Chronic Medical Conditions. Journal of Psychosomatic Research, 57, 565-571. http://dx.doi.org/10.1016/j.jpsychores.2004.04.367

Lagerveld, S. E., Bültmann, U., Franche, R. L., Dijk, F. J., Vlasveld, M. C., Feltz-Cornelis, C. M., Klink, J. J. et al. (2010). Factors Associated with Work Participation and Work Functioning in Depressed Workers: A Systematic Review. Journal of Occupational Rehabilitation, 20, 275-292. http://dx.doi.org/10.1007/s10926-009-9224-x

Machado, M., Iskedjian, M., Ruiz, I., \& Einarson, T. R. (2006). Remission, Dropouts, and Adverse Drug Reaction Rates in Major Depressive Disorder: A Meta-Analysis of Head-to-Head Trials. Current Medical Research \& Opinion, 22, 18251837. http://dx.doi.org/10.1185/030079906X132415

Manchikanti, L., Giordano, J., Boswell, M., Fellows, B., Manchukonda, R., \& Pampati, V. (2007). Psychological Factors as Predictors of Opioid Abuse and Illicit Drug Use in Chronic Pain Patients. Journal of Opioid Management, 3, 89-100.

Mohr, D. C., Hart, S. L., Howard, I., Julian, L., Vella, L., Catledge, C., \& Feldman, M. D. (2006). Barriers to Psychotherapy among Depressed and Nondepressed Primary Care Patients. Annals of Behavioral Medicine, 32, 254-258. http://dx.doi.org/10.1207/s15324796abm3203_12

Mulder, R. T. (2002). Personality Pathology and Treatment Outcome in Major Depression: A Review. The American Journal of Psychiatry, 159, 359-371. http://dx.doi.org/10.1176/appi.ajp.159.3.359 
National Committee for Quality Assurance (2007). HEDIS 2008 Technical Specifications. City name: National Committee for Quality Assurance.

Olfson, M., Marcus, S. C., Tedeschi, M., \& Wan, G. J. (2006). Continuity of Antidepressant Treatment for Adults with Depression in the United States. The American Journal of Psychiatry, 163, 101-108. http://dx.doi.org/10.1176/appi.ajp.163.1.101

Olfson, M., Mojtabai, R., Sampson, N. A., Hwang, I., Druss, B., Wang, P. S., Kessler, R. C. et al. (2009). Dropout from Outpatient Mental Health Care in the United States. Psychiatric Services, 60, 898-907. http://dx.doi.org/10.1176/ps.2009.60.7.898

Pampallona, S., Bollini, P., Tibaldi, G., Kupelnick, B., \& Munizza, C. (2004). Combined Pharmacotherapy and Psychological Treatment for Depression: A Systematic Review. JAMA Psychiatry, 61, 714-719. http://dx.doi.org/10.1001/archpsyc.61.7.714

Rhee, Y., Taitel, M. S., Walker, D. R., \& Lau, D. T. (2007). Narcotic Drug Use among Patients with Lower Back Pain in Employer Health Plans: A Retrospective Analysis of Risk Factors and Health Care Services. Clinical Therapeutics, 29, 2603-2612. http://dx.doi.org/10.1016/j.clinthera.2007.12.006

Rost, K., Nutting, P., Smith, J., Coyne, J. C., Cooper-Patrick, L., \& Rubenstein, L. (2000). The Role of Competing Demands in the Treatment Provided Primary Care Patients with Major Depression. Archives of Family Medicine, 9, 150-154. http://dx.doi.org/10.1001/archfami.9.2.150

Simon, G. E. (2003). Social and Economic Burden of Mood Disorders. Biological Psychiatry, 54, 208-215. http://dx.doi.org/10.1016/S0006-3223(03)00420-7

Stewart, W. F., Ricci, J. A., Chee, E., Hahn, S. R., \& Morganstein, D. (2003). Cost of Lost Productive Work Time among US Workers with Depression. JAMA, 289, 3135-3144. http://dx.doi.org/10.1001/jama.289.23.3135

Stranges, E., Yu, J., Kassed, C., Mark, T., Coffey, R., Houchens, R., Marder, W. (2009). Diagnosed Depression Associated with Higher Risk of Physical Comorbidities. Ann Arbor, MI: Truven Health Analytics.

Sung, H. N., Chae, H. S., Kim, E. S., \& Kim, J. S. (2014). Diabetes and Depressive Symptoms in Korean Women: The Fifth Korean National Health and Nutrition Examination Survey (2010-2011). Korean Journal of Family Medicine, 35, $127-135$. http://dx.doi.org/10.4082/kjfm.2014.35.3.127

Tai-Seale, M., Croghan, T. W., \& Obenchain, R. (2000). Determinants of Antidepressant Treatment Compliance: Implications for Policy. Medical Care Research and Review, 57, 491-512. http://dx.doi.org/10.1177/107755870005700405

Vowles, K. E., \& McCracken, L. M. (2008). Acceptance and Values-Based Action in Chronic Pain: A Study of Treatment Effectiveness and Process. Journal of Consulting and Clinical Psychology, 76, 397-407. http://dx.doi.org/10.1037/0022-006X.76.3.397

Wang, P. S., Lane, M., Olfson, M., Pincus, H. A., Wells, K. B., \& Kessler, R. C. (2005). Twelve-Month Use of Mental Health Services in the United States: Results from the National Comorbidity Survey Replication. JAMA Psychiatry, 62, 629-640. http://dx.doi.org/10.1001/archpsyc.62.6.629

Warden, D., Rush, A. J., Carmody, T. J., Kashner, T. M., Biggs, M. M., Crismon, M. L., \& Trivedi, M. H. (2009). Predictors of Attrition during One Year of Depression Treatment: A Roadmap to Personalized Intervention. Journal of Psychiatric Practice, 15, 113-124. http://dx.doi.org/10.1097/01.pra.0000348364.88676.83

Warden, D., Trivedi, M. H., Wisniewski, S. R., Davis, L., Nierenberg, A. A., Gaynes, B. N., Howland, R. et al. (2007). Predictors of Attrition during Initial (Citalopram) Treatment for Depression: A STAR*D Report. The American Journal of Psychiatry, 164, 1189-1197. http://dx.doi.org/10.1176/appi.ajp.2007.06071225

Weilburg, J. B., O’Leary, K. M., Meigs, J. B., Hennen, J., \& Stafford, R. S. (2003). Evaluation of the Adequacy of Outpatient Antidepressant Treatment. Psychiatric Services, 54, 1233-1239. http://dx.doi.org/10.1176/appi.ps.54.9.1233

Young, A. S., Klap, R., Sherbourne, C. D., \& Wells, K. B. (2001). The Quality of Care for Depressive and Anxiety Disorders in the United States. JAMA Psychiatry, 58, 55-61. http://dx.doi.org/10.1001/archpsyc.58.1.55 